\title{
Metastatic colorectal cancer and severe hypocalcemia following irinotecan administration in a patient with X-linked agammaglobulinemia: a case report
}

Mingming $\mathrm{Li}^{1+}$, Wei Chen ${ }^{1+}$, Xiaomeng Sun ${ }^{2}$, Zhipeng Wang ${ }^{1}$, Xun Zou ${ }^{1}$, Hua Wei ${ }^{1}$, Zhan Wang ${ }^{3^{*}}$ and Wansheng Chen $^{1 *}$ (D)

\begin{abstract}
Background: $X$-linked agammaglobulinemia $(X L A)$ is a primary immunodeficiency disorder caused by germline mutations in the Bruton tyrosine kinase (BTK) gene on X chromosome. These mutations disturb B-cell development, decrease immunoglobulin levels, increase susceptibility to infection or neoplasms, and increase the risk of developing colorectal cancer (CRC). For occasional cases of CRC have been reported in XLA patients, low levels of $B$ lymphocytes and immunoglobulins induced by congenital immune disorder make them more susceptible to drugrelated toxicities (DRT). Therefore, gene sequencing, therapeutic drug monitoring and any possible measurement to predict DRT should be considered before determining the course of chemotherapy for XLA patients with CRC.

Case presentation: In this study, we reported a 21 -year-old male who developed metastatic CRC in the context of $X L A$. Since the whole exome sequencing and therapeutic drug monitoring did not reveal any predictive markers of DRT, we applied standard first-line chemotherapy to the patient. However, progressive disease occurred after the fifth treatment cycle. Therefore, the administration of oxaliplatin was changed to irinotecan as second-line therapy. After that, the patient firstly suffered from severe hypocalcemia and eventually died due to metastatic CRC after the eighth treatment cycle. The overall survival time was 7.5 months.

Conclusions: This study reported the first written record of a Chinese XLA patient with metastatic CRC and severe hypocalcemia. Whole exome sequencing and bioinformatic analysis indicated the somatic mutations in $A B C A 6, C 6$ and PAX3 genes might contribute to the early-onset and metastasis CRC. Besides, a number of germline mutations in genes related to calcium metabolism (CACNA2D4, CD36, etc.) and the administration of irinotecan were speculated to be the causes of severe hypocalcemia. We therefore suggested that in order to avoid severe DRT, clinicians should take genetic background and therapeutic drug monitoring into consideration while planning chemotherapy treatment for XLA patients with CRC.
\end{abstract}

Keywords: X-linked agammaglobulinemia, Hypocalcemia, Whole exome sequencing, Therapeutic drug monitoring, And irinotecan

\footnotetext{
*Correspondence: profoundamir@smmu.edu.cn;

chenwansheng@smmu.edu.cn

${ }^{\dagger}$ Mingming Li and Wei Chen contributed equally to this work.

${ }^{3}$ Department of Oncology, Changzheng Hospital, Secondary Military Medical University, Shanghai, China

'Department of Pharmacy, Changzheng Hospital, Secondary Military Medical

University, Shanghai, China

Full list of author information is available at the end of the article
}

(c) The Author(s). 2019 Open Access This article is distributed under the terms of the Creative Commons Attribution 4.0 International License (http://creativecommons.org/licenses/by/4.0/), which permits unrestricted use, distribution, and reproduction in any medium, provided you give appropriate credit to the original author(s) and the source, provide a link to the Creative Commons license, and indicate if changes were made. The Creative Commons Public Domain Dedication waiver (http://creativecommons.org/publicdomain/zero/1.0/) applies to the data made available in this article, unless otherwise stated. 


\section{Background}

$\mathrm{X}$-linked agammaglobulinemia (XLA) is an X-linked inherited disease caused by genetic mutations in the Bruton tyrosine kinase (BTK) gene [1, 2], which suppress the development of mature B lymphocytes. The human BTK gene encompasses $37.5 \mathrm{~kb}$ containing 19 exons. BTKbase is an up-to-date database compiling 1796 entities showing 917 unique BTK mutations from 1749 individuals, two thirds of which are from unrelated families, while one third are believed to be sporadic cases [3]. These mutations are found throughout the entire $B T K$ gene sequence. The incidence of XLA varies between $1 / 200,000$ and $1 / 20,000,000$ in Western countries, whereas it has not been calculated in China yet [4]. Based on estimation, there should be more than 1000 cumulative XLA cases below 14 years of age [5].

XLA patients are characterized by insufficient number of normal circulating B lymphocytes and immunoglobulins [6]. The concurrent hallmark symptoms and complications of XLA include lower respiratory tract infection (bronchitis/pneumonia), otitis media, persistent diarrhea and skin infections $[7,8]$. XLA patients are also susceptible to certain types of cancer including colorectal cancer (CRC) [9-15]. According to the National Comprehensive Cancer Network (NCCN) guidelines for colon cancer and rectal cancer, 5fluorouracil (5-FU)-based drugs are recommended and commonly used for first-line chemotherapy [16]. But patients receiving 5-FU-based chemotherapy, alone or in a combination regimen, may experience drug-related toxicities (DRT) involving hand-foot syndrome, leukopenia, neutropenia, thrombocytopenia, diarrhea, nausea and vomiting [17]. Severe DRT not only leads to an early termination of chemotherapy but also causes safety issues. With previous evidence of lymphopenia being an independent factor associated with first-line chemotherapy induced hematologic toxicities in CRC patients $[18,19]$, we assume that XLA patients, who are characterized by low levels of B lymphocytes and immunoglobulins, are more likely to develop DRTs when they are diagnosed with $\mathrm{CRC}$ and receive chemotherapy [11]. Therefore, gene sequencing, therapeutic drug monitoring and any possible measurement to predict DRT should be considered before making chemotherapy regimens for XLA patients with CRC.

\section{Case presentation}

\section{Presenting concerns}

A 21-year-old man with XLA was hospitalized for fecal occult blood, epigastric pain and bronchitis in 2016. The patient was not married. The timeline of hospitalization is shown in Fig. 1a.

\section{Clinical findings}

This patient was diagnosed with XLA when he was 4 years old. He had no family history of XLA. Regular intravenous immunoglobulin (IVIG) replacement therapy was applied since the diagnosis. The admission physical examination found no positive symptoms of XLA.

\section{Diagnostic focus and assessment}

Abdominal ultrasonography showed multiple hepatic parenchymal lesions, gallbladder stones, splenomegaly and a hypoechoic mass in the right lower abdomen. Colonoscopy showed a cauliflower-like mass in the ascending colon. Needle biopsy of focal liver lesions (Fig. 1b) and PET-CT (Fig. 1c) suggested metastatic adenocarcinoma. The Eastern Cooperative Oncology Group (ECOG) Performance Status was one [20].

Whole exome sequencing (WES) was conducted using blood and liver tumor tissue. It revealed 10 somatic (Table 1) and 200 germline SNVs, including one on the BTK gene (c.340_347del, p.F114delX115) (Additional file 2: Figure S1). Somatic mutation was absent in KRAS, NRAS, BRAF, or PIK3CA. There is also no mutation in genes related to efficacy or safety of 5-FU-based drugs (Additional file 3: Table S1).

\section{Therapeutic focus and assessment}

Standard first-line chemotherapy was started on Nov. 18th, 2016. The regimen is as follows: $130 \mathrm{mg} / \mathrm{m}^{2}$ oxaliplatin iv on day $1,1000 \mathrm{mg} / \mathrm{m}^{2}$ capecitabine (Cap) twice po daily for 14 days, which was repeated every 3 weeks, and $500 \mathrm{mg} / \mathrm{m}^{2}$ cetuximab iv over $2 \mathrm{~h}$ on day 1 every 2 weeks. The tumor was stabilized after the first two treatment cycles (Fig. 1d-e), and the abdominal pain ceased, the abdominal lump was reduced, and CA-199 (from 1410 to $157 \mathrm{U} / \mathrm{ml}$ ) and CEA (from 113.6 to $20.1 \mu \mathrm{g} / \mathrm{L})$ levels decreased. During the second treatment cycle, TDM on Cap and its metabolites was conducted. Compared to 10 other random CRC patients without XLA, the XLA patient showed delayed Cmax of Cap, lower doxifluridine (5'-DFUR) level and higher 5-FU level (Fig. 2). These results suggested that the XLA patient had a slower ability to absorb Cap and increased thymidine phosphorylase (TYMP) activity. Since both low 5 '-DFUR levels and induced TYMP activity are negatively associated with Cap-related toxicity $[21,22]$ and this patient did not show any sign of DRT, the original chemotherapy plan was not adjusted.

\section{Follow-up and outcomes}

After the fifth treatment, the metastatic tumor progressed (PFS $4.2 \mathrm{~m}$ ) (Fig. 1f-g). The patient also experienced upper abdominal pain, an upper respiratory tract infection and a severe rash. From the sixth treatment, oxaliplatin was changed to irinotecan $\left(180 \mathrm{mg} / \mathrm{m}^{2}\right.$ iv over 30 90 min on day 1). After the sixth treatment cycle, hypocalcemia (mean, $5.8 \mathrm{mg} / \mathrm{dL}$; range, $4.3-8.2 \mathrm{mg} / \mathrm{dL}$; diagnostic lower limit, $14.0 \mathrm{mg} / \mathrm{dL}$ ) and a tendency of hypokalemia 


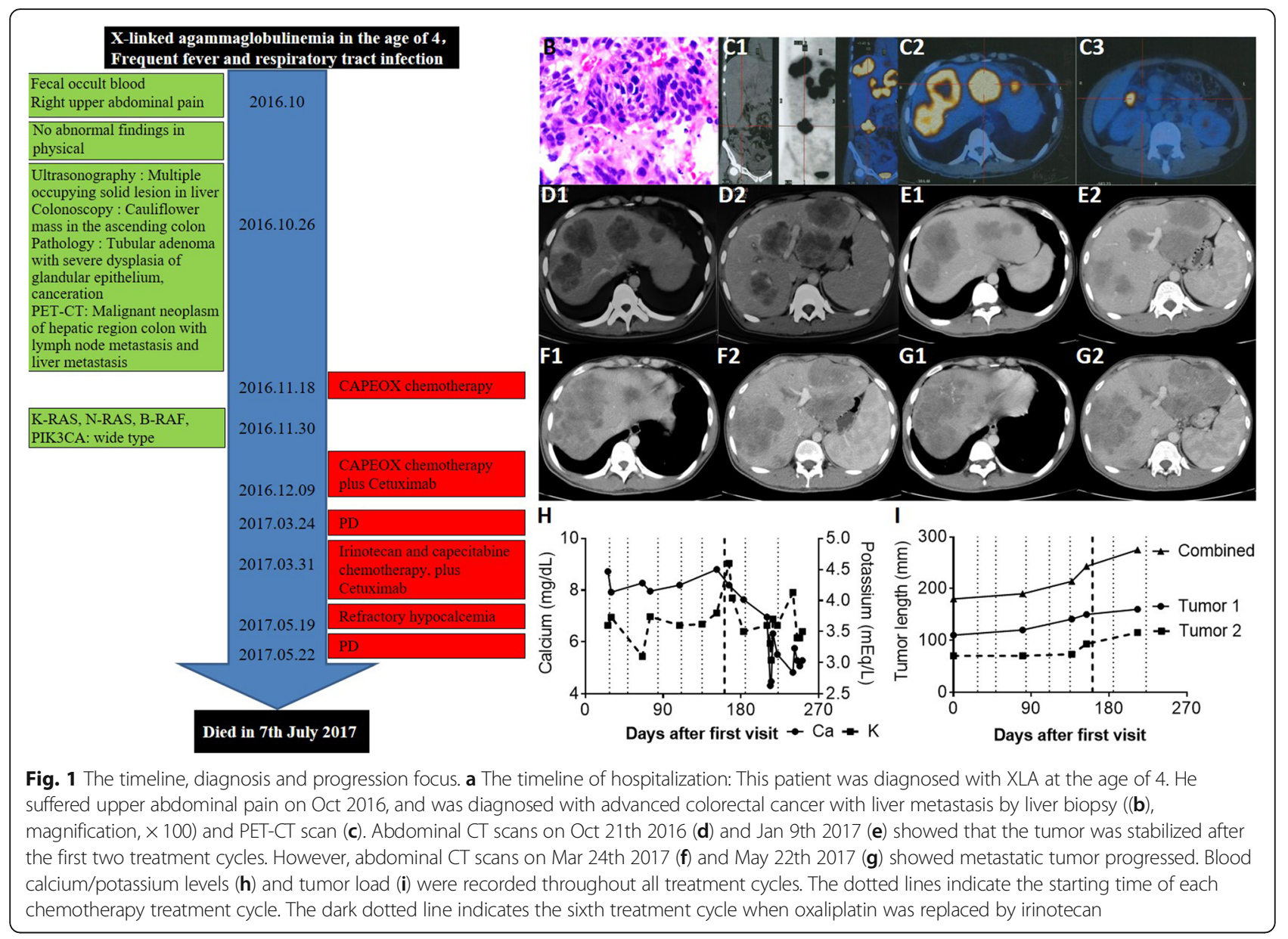

Table 1 Somatic variants may initiate tumor development

\begin{tabular}{|c|c|c|c|c|c|c|}
\hline SNP ID & Gene & Chrs & $\begin{array}{l}\text { Gene } \\
\text { Region }\end{array}$ & Function & $\begin{array}{l}\text { Cancer-promoting } \\
\text { gene }\end{array}$ & Diseases \\
\hline rs188382333 & ABCA6 & 17 & exonic & $\begin{array}{l}\text { nonsynonymous } \\
\text { SNV }\end{array}$ & Y & Colorectal cancer, acute myeloid Leukemia \\
\hline rs201064036 & C6 & 5 & exonic & $\begin{array}{l}\text { nonsynonymous } \\
\text { SNV }\end{array}$ & Y & C6 deficiency \\
\hline rs79930314 & CCDC144NL & 17 & exonic & Stop gain & $\mathrm{N}$ & Colorectal cancer; Renal cancer \\
\hline rs41291550 & CYP2C18 & 10 & exonic & Stop gain & $\mathrm{N}$ & NA \\
\hline rs1799931 & NAT2 & 8 & exonic & $\begin{array}{l}\text { nonsynonymous } \\
\text { SNV }\end{array}$ & $\mathrm{N}$ & Slow acetylation \\
\hline rs192410865 & NOX3 & 6 & exonic & Stop gain & $\mathrm{N}$ & NA \\
\hline $\begin{array}{l}\text { NM_000438:exon2:c.232G>A: } \\
\text { p.V78M }\end{array}$ & PAX3 & 2 & exonic & $\begin{array}{l}\text { nonsynonymous } \\
\text { SNV }\end{array}$ & Y & $\begin{array}{l}\text { Alveolar rhabdomyosarcomas, type } 1 \text { and type } 3 \\
\text { Waardenburg syndrome }\end{array}$ \\
\hline rs138133378 & SCN7A & 2 & exonic & $\begin{array}{l}\text { nonsynonymous } \\
\text { SNV }\end{array}$ & $\mathrm{N}$ & NA \\
\hline rs117153533 & TC2N & 14 & exonic & $\begin{array}{l}\text { nonsynonymous } \\
\text { SNV }\end{array}$ & $\mathrm{N}$ & Colorectal cancer, \\
\hline rs201277886 & TOX & 8 & exonic & $\begin{array}{l}\text { nonsynonymous } \\
\text { SNV }\end{array}$ & $\mathrm{N}$ & $\begin{array}{l}\text { Colorectal cancer, virus-associated hepatocellular } \\
\text { cancer, gastric cancer, esophageal cancer }\end{array}$ \\
\hline
\end{tabular}

Each SNP was searched in the following databases to confirm its correlation with diseases and whether it belongs to a cancer-promoting gene: ClinVar, ICGC, COSMIC, HGMD and OMIM 


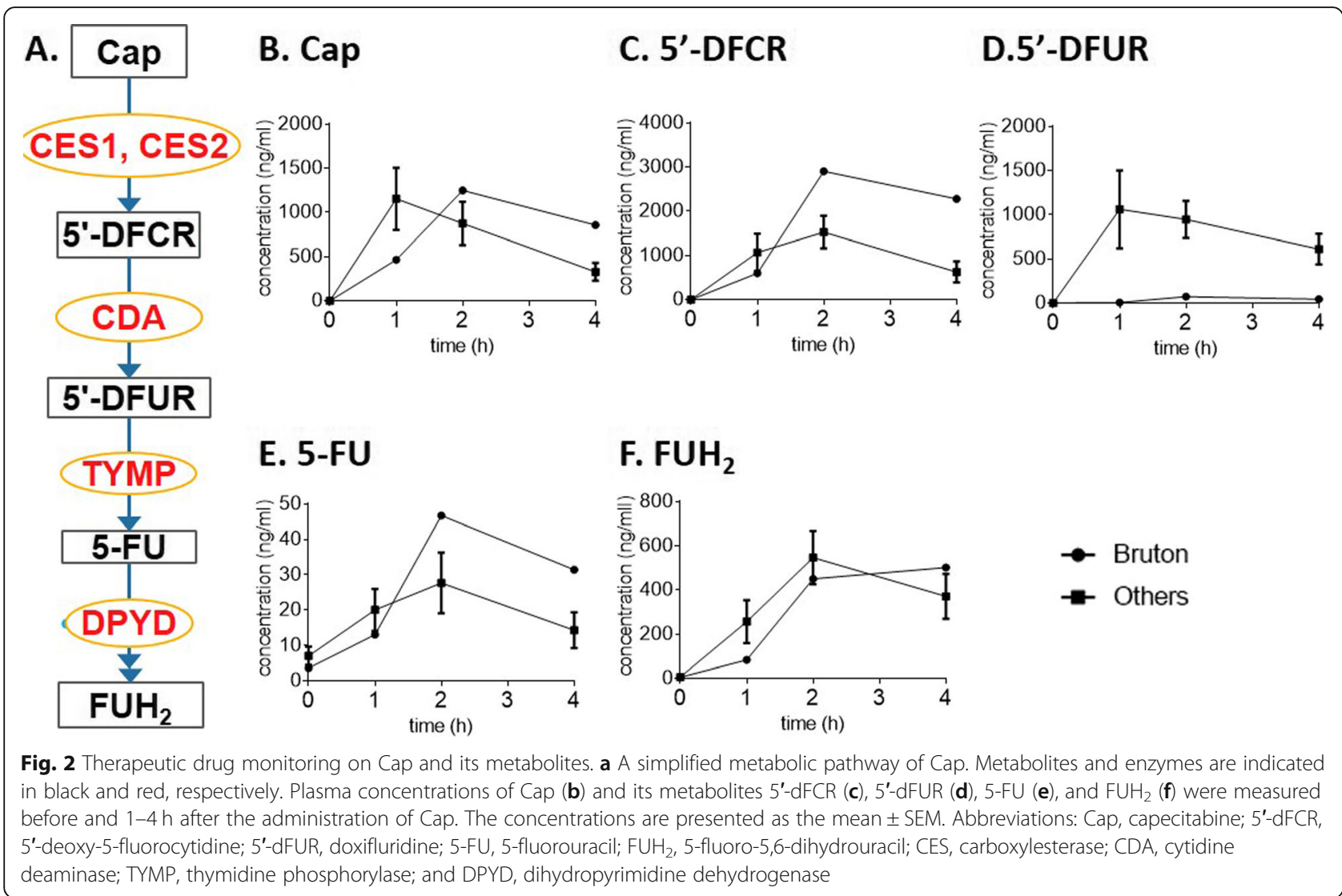

(mean, 142.4 mEq/L; range, 118.6-161.1 mEq/L; diagnostic lower limit, $136.5 \mathrm{mEq} / \mathrm{L}$ ) were observed (Fig. 1h). They were not relieved by intravenous calcium gluconate supplementation ( $1 \mathrm{~g}$, twice daily).

Prior to the eighth treatment, a CT examination revealed an increase in total liver mass (Fig. 1i), which indicated PD (PFS $1.3 \mathrm{~m}$ ). Unfortunately, the condition of the patient deteriorated with severe ascites and infection. Finally, best supportive care lasted for 1 month before he died (OS was $7.5 \mathrm{~m}$ ).

\section{Discussion and conclusions}

Primary immunodeficiency caused by the BTK mutation is the main reason for XLA-associated diseases, which include recurrent bacterial infections, arthritis and types of cancer [23, 24]. In this study, the diagnosis of XLA was confirmed by WES, where a hemizygous pathogenic mutation (c.340_347del, p.F114delX115) of the BTK gene was found (Additional file 1). The $8 \mathrm{bp}$ deletion of TTCTCCCC resulted in a frameshift mutation that affected general membrane targeting and the regulatory function of BTK [25]. Immunohistochemistry showed similar low expression of BTK in the tumor and tumoradjacent tissue (Additional file 4: Figure S2).

It has been hypothesized that male XLA patients tend to have an early-onset CRC $[11,12]$. B-cell deficiency is a risk factor for a narrow range of solid cancers, including CRC [26]. However, the correlation between CRC and XLA has not yet been statistically confirmed with a reasonable sample size. One study found colorectal adenomatous polyps from 2 out of 4 XLA patients in the Netherlands [27]. However, two other studies found that among 44 and 27 XLA patients from the United Kingdom and mainland China, respectively, none of the patients developed CRC $[5,28]$. In the case studied in this report, the onset of CRC was more likely due to sporadic colorectal mutations. First, the XLA patient had no family history of immunodeficiency within 3 generations. Second, among the 10 somatic variants, the most convincing candidate CRC-driver mutations in $A B C A 6, C 6$, and $P A X 3$ provided by the DriverDBv2 database are not functionally related [29]. C6 encodes for one of the membrane attack proteins, which plays a key role in the innate and adaptive immune responses by forming pores in the plasma membrane of target cells. It has been shown that dextran-sulfate-sodium (DSS) induced colitis was aggravated in C6-deficient mice with a series of enhanced production of pro-inflammatory mediators, including $I L-1 \beta, I L-6, C X C L-1, C C L-3, T G F-\beta 1$ and $I L-17 F$, compared with wild-type mice [30]. In addition, exogenous C6 could ameliorate DSS-induced colitis in C6-deficient mice [30]. Since both colitis and enhanced inflammatory are risk factors of colorectal cancer, 
Table 2 Germline variants related to calcium metabolism

\begin{tabular}{|c|c|c|c|c|c|}
\hline SNP ID & Gene & Chrs & Gene Region & Function & Calcium-related function or diseases \\
\hline p.F114delX115 & BTK & $x$ & exonic & nonsynonymous SNV & Induces calcium mobilization and calcium-mediated signaling. \\
\hline rs202054008 & CACNA2D4 & 4 & exonic & nonsynonymous SNV & $\begin{array}{l}\text { Regulates calcium current density and activation/inactivation } \\
\text { of calcium channels }\end{array}$ \\
\hline rs75326924 & CD36 & 3 & exonic & nonsynonymous SNV & Regulates intracellular calcium levels by long-chain fatty acids. \\
\hline rs2229291 & CPT2 & 15 & splicing & NA & Calcium metabolism and abnormal calcium deposition. \\
\hline rs3888798 & CTSC & $x$ & exonic & frameshift deletion & $\begin{array}{l}\text { Deposition of calcium salts in a tissue or location in which } \\
\text { calcification does not normally occur. }\end{array}$ \\
\hline rs147630160 & CXCL16 & 10 & exonic & nonsynonymous SNV & Induces calcium mobilization. \\
\hline rs117643139 & DRD2 & 4 & exonic & nonsynonymous SNV & Pituitary adenoma-related hypokalemia and hypocalcemia [42] \\
\hline rs139997095 & PKD1L2 & 7 & exonic & nonsynonymous SNV & Calcium ion transmembrane transport. \\
\hline rs201550522 & PRSS1 & 6 & exonic & nonsynonymous SNV & $\begin{array}{l}\text { Deposition of calcium salts in a tissue or location in which } \\
\text { calcification does not normally occur. }\end{array}$ \\
\hline rs201533738 & SLX4 & 7 & exonic & nonsynonymous SNV & Calcium metabolism. \\
\hline rs182693954 & TRPV1 & 12 & exonic & nonsynonymous SNV & $\begin{array}{l}\text { Ligand-activated nonselective calcium permeant cation channel } \\
\text { involved in the detection of noxious chemical and thermal stimuli. }\end{array}$ \\
\hline
\end{tabular}

the deficiency of $C 6$ may also participate in CRC development [31]. PAX3 encodes a transcription factor with an $\mathrm{N}$-terminal DNA binding domain consisting of a paired box. It acts as a transcriptional regulator to activate or repress target genes of carcinogenesis [32, 33]. ABCA6 is a member of the ATP-binding cassette transporter family. It is ubiquitously expressed in the liver, heart and brain, contributing to drug resistance and tumor metastasis [34, 35]. In addition to these cancer-promoting mutations, the mutation (c.857G > A) of $\mathrm{N}$-acetyltransferase 2 (NAT2) has been shown to be associated with slow acetylator phenotypes, which is normally correlated with the effectiveness of drugs and xenobiotic toxicity [36].

Because the incidence of CRC in China has increased rapidly over the past two decades [37, 38], and XLA patients are more prone to carcinogenesis. It is suggested to begin surveillance programs on XLA patients for CRC screening, especially for patients over the age of 20 and 30. As most XLA patients with gastric cancer or CRC have been found at these ages [23].

Regarding severe hypocalcemia, it is speculated to be a joint result of a number of germline mutations in genes related to calcium metabolism and the administration of irinotecan. First, based on the enrichment analysis of genes having germline mutations, the largest enriched group was calcium-related proteins $(n=48, p=1.2 \mathrm{E}-7)$ (Additional file 5 and Additional file 6: Table S2). This group contains genes that bind at least one calcium atom or proteins whose function is calcium-dependent [39-41]. Among them, 11 genes are directly involved in calcium metabolism and transportation (Table 2). Mutations in these genes may make the patient prone to abnormal calcium metabolism such as hypocalcemia. Second, the onset of hypocalcemia occurred immediately after the administration of irinotecan. Several studies have reported that hypocalcemia may be one of the rare DRTs of irinotecan (Table 3). Most of these cases had concurrent electrolyte abnormalities such as hypokalemia and hypomagnesemia. Consistently, the patient in this study also showed a trend of hypokalemia (Fig. 2j). However, the magnesium level was not measured in this study.

In conclusion, this study reported the first written record of a Chinese XLA patient with metastatic CRC and severe hypocalcemia following irinotecan administration. The chemotherapy regimen was carefully determined

Table 3 Reported cases showing a positive association between irinotecan and hypocalcemia

\begin{tabular}{|c|c|c|c|c|c|c|c|}
\hline Case & Country & Tumor & Stage & Age & Drug treatment & Serum electrolyte abnormalities & Onset time \\
\hline 2003 [43] & United states & Solid tumors & NA & $4-21$ & $\begin{array}{l}\text { Cisplatin, irinotecan, } \\
\text { amifostine }\end{array}$ & Hypocalcemia & $\begin{array}{l}\text { Within } 24 \mathrm{~h} \text { after } 1 \mathrm{st} \\
\text { treatment }\end{array}$ \\
\hline $2005[44,45]$ & United states & Colorectal cancer & TxNxM1 & 34 & Cetuximab, irinotecan & Hypocalcemia, hypomagnesemia & $\begin{array}{l}8 \text { weeks after 1st } \\
\text { treatment }\end{array}$ \\
\hline $2009[46]$ & United states & Colorectal cancer & T3N2M0 & 77 & $\begin{array}{l}\text { Cap, irinotecan, } \\
\text { bevacizumab }\end{array}$ & $\begin{array}{l}\text { Hypocalcemia, hypophosphatemia, } \\
\text { hypokalemia, hypouricemia }\end{array}$ & $\begin{array}{l}5 \text { days after the } 11 \text { th } \\
\text { treatment }\end{array}$ \\
\hline 2010 [47] & Japan & Colorectal cancer & TxNxM1 & 61 & Cetuximab, irinotecan & Hypocalcemia, hypomagnesemia & NA \\
\hline 2012 [48] & Turkey & Breast cancer & T2NOMO & 57 & Irinotecan, trastuzumab & $\begin{array}{l}\text { Hypokalemia, hypocalcemia, } \\
\text { hypomagnesemia }\end{array}$ & 6th week of treatment \\
\hline
\end{tabular}


based on TDM and WES. Based on WES results and bioinformatic analysis, a germline mutation of BTK was confirmed to be the cause of XLA, and somatic mutations of $A B C A 6, C 6$, and $P A X 3$ may contribute to the onset and metastasis of CRC. The administration of irinotecan and a number of germline mutations on genes related to calcium metabolism might collectively cause hypocalcemia.

\section{Additional files}

Additional file 1: Methods of DNA sequencing and screening. The detailed method used for carrying out DNA sequencing and screening was described in words with references. (DOCX $42 \mathrm{~kb}$ )

Additional file 2: Figure S1. Variant filtering pipeline for Whole Exome Sequencing. The step-by-step flow chart for whole exosome sequencing was illustrated with key nodes. (DOCX $116 \mathrm{~kb}$ )

Additional file 3: Table S1. Mutations that related to efficacy (or safety) of 5-FU-like drugs. The self-selected genes or SNVs which may affect the efficacy or safety of 5-FU-based chemotherapy were listed with references. They were sub-grouped into three types which are related to 5-FU metabolism, cancer development (oncogenes), or lipid metabolism respectively. (DOCX $202 \mathrm{~kb}$ )

Additional file 4: Figure S2. BTK expression in liver tumor tissue. BTK expression in liver tumor tissue was positively illustrated by immunohistochemistry. (DOCX $1843 \mathrm{~kb}$ )

Additional file 5: Germline variants illuminating hypocalcemia. Bioinformatic analysis on germline variants indicated that many of these variants were related to calcium binding and transporting, several of them might even be the main reason for the hypocalcemia. (DOCX $29 \mathrm{~kb}$ )

Additional file 6: Table S2. Germline variants related calcium binding and transporting. All of the germline line variants related to calcium binding and transporting were listed here with annotations on whether it is cancer related and its gene function. (DOCX $34 \mathrm{~kb}$ )

\section{Abbreviations \\ 5'-DFUR: Doxifluridine; 5-FU: 5-fluorouracil; ABCA6: ATP-Binding Cassette Subfamily A Member 6; BTK: Bruton tyrosine kinase; C6: Complement C6; Cap: Capecitabine; CRC: Colorectal cancer; DRT: Drug-related toxicities; ECOG: Eastern Cooperative Oncology Group; IVIG: Intravenous immunoglobulin; NAT2: N-acetyltransferase 2; NCCN: The National Comprehensive Cancer Network; PAX3: Paired Box 3; TDM: Therapeutic drug monitoring; TGFB1: Transcription of transforming growth factor beta 1; TYMP: Thymidine phosphorylase; WES: Whole exome sequencing; XLA: X- linked agammaglobulinemia}

\section{Acknowledgments}

The authors gratefully acknowledge the Shanghai Committee of Science and Technology at the Shanghai Shenkang Hospital Development Center for providing funding and resources and Genesky Biotechnologies, Inc., Shanghai for preforming WES. The funders had no role in the study design, data collection, analysis, decision to publish, or preparation of the manuscript.

\section{Authors' contributions}

WZ and CWS were responsible for the treatment of the patient. LMM wrote and revised the manuscript. CW collected clinical information and samples for the analyses and produced critical figures and tables for this manuscript. SXM revised and interpreted the WES data. WZP and ZX performed the TDM experiments. WH offered constructive suggestions for this study. All authors have read and approved the final manuscript.

\section{Funding}

During the whole course of this study, the study design, data collection, data analysis, data interpretation and manuscript preparation were mainly supported by the National International Scientific and Technological
Cooperation Program, China (Grant No. 2015DFA31810). Part of the data analysis, which is the therapeutic drug monitoring was supported by the Clinical Science and Technology Innovation Project, Shanghai, China (Grant No. SHDC12015120).

\section{Availability of data and materials}

The datasets used and/or analyzed during the current study are available from the corresponding author upon a reasonable request.

\section{Ethics approval and consent to participate}

The study was approved by the Changzheng Hospital Biomedical Research Ethics Committee. The patients and their families have read and signed the informed consent form.

\section{Consent for publication}

Written informed consent was obtained from all patients included in this report for the use of clinical-related materials for scientific research and publications. These materials include diagnostic images, treatment and prognostic information, genetic testing results and other related data used in this report.

\section{Competing interests}

The authors declare that they have no competing interests.

\section{Author details}

'Department of Pharmacy, Changzheng Hospital, Secondary Military Medical University, Shanghai, China. ${ }^{2}$ Institutes of Biomedical Sciences, Fudan University, Shanghai, China. ${ }^{3}$ Department of Oncology, Changzheng Hospital, Secondary Military Medical University, Shanghai, China.

Received: 30 November 2018 Accepted: 22 August 2019

Published online: 12 September 2019

\section{References}

1. Tsukada S, Saffran DC, Rawlings DJ, Parolini O, Allen RC, Klisak I, et al. Deficient expression of a B cell cytoplasmic tyrosine kinase in human Xlinked agammaglobulinemia. Cell. 1993;72:279-90.

2. Vetrie D, Vořechovský I, Sideras $P$, Holland J, Davies A, Flinter F, et al. Pillars Article: The Gene Involved in X-linked Agammaglobulinaemia Is a Member of the Src Family of Protein-Tyrosine Kinases. Nature. 1993;361:226-33 The Journal of Immunology. 2012;188:2948-55.

3. Wilkie A, Vetrie D, Vorechovsky I, Sideras P, Holland J, Davies A, et al. The gene involved in $\mathrm{X}$-linked agammaglobulinaemia is a member of the src family of protein-tyrosine kinases. J Med Genet. 1993;30:444.

4. Väliaho J, Smith CIE, Vihinen M. BTKbase: the mutation database for X-linked agammaglobulinemia. Hum Mutat. 2006;27:1209-17.

5. Wang $Y$, Kanegane $H$, Wang $X$, Han X, Zhang Q, Zhao S, et al. Mutation of the BTK gene and clinical feature of $X$-linked agammaglobulinemia in mainland China. J Clin Immunol. 2009;29:352-6.

6. Ochs HD, Smith Cl. X-linked agammaglobulinemia. A clinical and molecular analysis. Medicine (Baltimore). 1996;75:287-99.

7. Van der Hilst JCH, Smits BW, van der Meer JWM. Hypogammaglobulinaemia: cumulative experience in 49 patients in a tertiary care institution. Neth J Med. 2002;60:140-7.

8. Chen X-F, Wang W-F, Zhang Y-D, Zhao W, Wu J, Chen T-X. Clinical characteristics and genetic profiles of 174 patients with X-linked agammaglobulinemia: report from Shanghai, China (2000-2015). Medicine. 2016;95:e4544.

9. Kinlen LJ, Webster AD, Bird AG, Haile R, Peto J, Soothill JF, et al. Prospective study of cancer in patients with hypogammaglobulinaemia. Lancet. 1985;1:263-6.

10. van der Meer JWM, van Munster IP, Nagengast FM, Weening RS, Schellekens PTA. Colorectal cancer in patients with X-linked agammaglobulinaemia. Lancet. 1993;341:1439-40.

11. Brosens LAA, Tytgat KMAJ, Morsink FHM, Sinke RJ, Berge IJMTEN, Giardiello FM, et al. Multiple colorectal neoplasms in X-linked Agammaglobulinemia. Clin Gastroenterol Hepatol. 2008;6:115-9.

12. Bachmeyer $\mathrm{C}$, Monge $\mathrm{M}$, Cazier $\mathrm{A}$, Le Deist $\mathrm{F}$, de Saint BG, Durandy A, et al. Gastric adenocarcinoma in a patient with X-linked agammaglobulinaemia. Eur J Gastroenterol Hepatol. 2000;12:1033-5. 
13. Lackmann GM, Wahn V, Poremba C, Niehues T. A teenager with X-linked agammaglobulinemia and vitamin B12 deficiency anemia. J Pediatr Gastroenterol Nutr. 2005;41:360-2.

14. Hajjar J, Hasan S, Forbes LR, Hemmige V, Orange JS. Gastric adenocarcinoma in a patient with X-linked Agammaglobulinemia and HIV case report and review of the literature. Front Pediatr. 2016:4:100.

15. Mueller BU, Pizzo PA. Cancer in children with primary or secondary immunodeficiencies. J Pediatr. 1995;126:1-10.

16. Benson AB, Venook AP, Al-Hawary MM, Cederquist L, Chen Y-J, Ciombor KK, et al. NCCN guidelines insights: Colon Cancer, version 2.2018. J Natl Compr Cancer Netw. 2018;16:359-69.

17. Kadoyama K, Miki I, Tamura T, Brown JB, Sakaeda T. Adverse Event Profiles of 5-Fluorouracil and Capecitabine : Data Mining of the Public Version of the FDA Adverse Event Reporting System, AERS, and Reproducibility of Clinical Observations; 2012

18. Cézé N, Thibault G, Goujon G, Viguier J, Watier H, Dorval E, et al. Pretreatment lymphopenia as a prognostic biomarker in colorectal cancer patients receiving chemotherapy. Cancer Chemother Pharmacol. 2011; 68:1305-13.

19. Kou F, Lu Z, Li J, Zhang X, Lu M, Zhou J, et al. Pretreatment lymphopenia is an easily detectable predictive and prognostic marker in patients with metastatic esophagus squamous cell carcinoma receiving first-line chemotherapy. Cancer Med. 2016;5:778-86.

20. Oken MM, Creech RH, Tormey DC, Horton J, Davis TE, McFadden ET, et al. Toxicity and response criteria of the eastern cooperative oncology group. Am J Clin Oncol. 1982:5:649-55.

21. Daher Abdi Z, Lavau-Denes S, Prémaud A, Urien S, Sauvage FL, Martin J, et al. Pharmacokinetics and exposure-effect relationships of capecitabine in elderly patients with breast or colorectal cancer. Cancer Chemother Pharmacol. 2014:73:1285-93.

22. Ab Mutalib N-S, Md Yusof NF, Abdul S-N, Jamal R. Pharmacogenomics DNA biomarkers in colorectal Cancer: current update. Front Pharmacol. 2017:8:736.

23. Staines Boone AT, Torres Martínez MG, López Herrera G, de Leija Portilla JO, Espinosa Padilla SE, Espinosa Rosales FJ, et al. Gastric adenocarcinoma in the context of X-linked agammaglobulinemia: case report and review of the literature. J Clin Immunol. 2014:34:134-7.

24. Sharma D, Gupta A, Goel S, Sharma M, Rawat A, Singh S. Large BTK gene mutation in a child with X-linked agammaglobulinemia and polyarthritis. Clin Immunol. 2017;183:109-11.

25. Saito K, Scharenberg AM, Kinet JP. Interaction between the Btk PH domain and phosphatidylinositol-3,4,5-trisphosphate directly regulates Btk. J Biol Chem. 2001:276:16201-6.

26. Wang X, Wang Y, Kanegane H, Toshio M, Yu Y. Gene diagnosis of X-linked agammaglobulinemia. Zhonghua er ke za zhi = Chin J Pediatr. 2005:43:449-52.

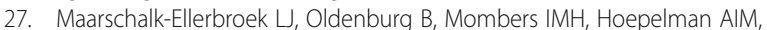
Brosens LA, GJA O, et al. Outcome of screening endoscopy in common variable immunodeficiency disorder and X-linked agammaglobulinemia. Endoscopy. 2013:45:320-3.

28. Fallah-Rad N, Ross MA. Managing hypercalcaemia and hypocalcaemia in cancer patients. Curr Opin Support Palliat Care. 2013;7:265-71.

29. Chung IF, Chen C-Y, Su S-C, Li C-Y, Wu K-J, Wang H-W, et al. DriverDBv2: a database for human cancer driver gene research. Nucleic Acids Res. 2016;44: D975-9.

30. Ding P, Li L, Huang T, Yang C, Xu E, Wang N, et al. Complement component 6 deficiency increases susceptibility to dextran sulfate sodiuminduced murine colitis. Immunobiology. 2016;221:1293-303.

31. Terzić J, Grivennikov S, Karin E, Karin M. Inflammation and colon cancer. Gastroenterology. 2010;138:2101-2114.e5.

32. Mayanil CS, George D, Freilich L, Miljan EJ, Mania-Farnell B, McLone DG, et al. Microarray analysis detects novel Pax3 downstream target genes. J Biol Chem. 2001;276:49299-309.

33. Wang Q, Fang W-H, Krupinski J, Kumar S, Slevin M, Kumar P. Pax genes in embryogenesis and oncogenesis. J Cell Mol Med. 2008;12:2281-94.

34. Hedditch EL, Gao B, Russell AJ, Lu Y, Emmanuel C, Beesley J, et al. ABCA transporter gene expression and poor outcome in epithelial ovarian Cancer Jnci-J Natl Cancer Inst. 2014;106(7):duj149. https://doi.org/10.1093/jnci/dju149.

35. Jelinek DF, Tschumper RC, Stolovitzky GA, Iturria SJ, Tu YH, Lepre J, et al. Identification of a global gene expression signature of B-chronic lymphocytic leukemia. Mol Cancer Res. 2003;1:346-61.

36. Magalon H, Patin E, Austerlitz F, Hegay T, Aldashev A, Quintana-Murci L, et al. Population genetic diversity of the NAT2 gene supports a role of acetylation in human adaptation to farming in Central Asia. Eur J Hum Genet. 2008;16:243-51.

37. Torre LA, Siegel RL, Ward EM, Jemal A. Global Cancer incidence and mortality rates and trends--an update. Cancer Epidemiol Biomark Prev. 2016; 25:16-27.

38. Zhang Q-L, Zhao L-G, Li H-L, Gao J, Yang G, Wang J, et al. The joint effects of major lifestyle factors on colorectal cancer risk among Chinese men: a prospective cohort study: combined lifestyle and colorectal cancer risk. Int J Cancer. 2018:142:1093-101.

39. Huang DW, Sherman BT, Lempicki RA. Bioinformatics enrichment tools: paths toward the comprehensive functional analysis of large gene lists. Nucleic Acids Res. 2009;37:1-13.

40. Huang DW, Sherman BT, Lempicki RA. Systematic and integrative analysis of large gene lists using DAVID bioinformatics resources. Nat Protoc. 2009:4:44-57.

41. Stelzer G, Plaschkes I, Oz-Levi D, Alkelai A, Olender T, Zimmerman S, et al. VarElect: the phenotype-based variation prioritizer of the GeneCards suite. BMC Genomics. 2016;17:444

42. Saif MW, Fekrazad MH, Ledbetter L, Diasio RB. Hypokalemia secondary to capecitabine: a hidden toxicity? Ther Clin Risk Manag. 2007;3:177-80.

43. Souid A-K, Dubowy RL, Blaney SM, Hershon L, Sullivan J, McLeod WD, et al. Phase I clinical and pharmacologic study of weekly cisplatin and irinotecan combined with amifostine for refractory solid tumors. Clin Cancer Res. 2003; 9:703-10.

44. Schrag D, Chung KY, Flombaum C, Saltz L. Cetuximab therapy and symptomatic hypomagnesemia. J Natl Cancer Inst. 2005:97:1221-4.

45. Altundag K, Altundag O, Baptista MZ, Turen S, Atik MA. Re: Cetuximab therapy and symptomatic hypomagnesemia. J Natl Cancer Inst. 2005;97: 1791-2.

46. Shaikh A, Wiisanen ME, Gunderson HD, Leung N. Acquired Fanconi syndrome after treatment with capecitabine, irinotecan, and bevacizumab. Ann Pharmacother. 2009;43:1370-3

47. Kono $T$, Satomi M, Asama T, Ebisawa $Y$, Chisato N, Suno M, et al. Cetuximabinduced hypomagnesaemia aggravates peripheral sensory neurotoxicity caused by oxaliplatin. J Gastrointest Oncol. 2010;1:97-101.

48. Petekkaya I, Akin T, Gezgen G, Roach EC, Ozisik Y, Altundag K. Electrolyte abnormalities due to irinotecan administration in metastatic HER-2 positive breast cancer patients. J BUON. 2012;17:800.

\section{Publisher's Note}

Springer Nature remains neutral with regard to jurisdictional claims in published maps and institutional affiliations.

\section{Ready to submit your research? Choose BMC and benefit from:}

- fast, convenient online submission

- thorough peer review by experienced researchers in your field

- rapid publication on acceptance

- support for research data, including large and complex data types

- gold Open Access which fosters wider collaboration and increased citations

- maximum visibility for your research: over $100 \mathrm{M}$ website views per year

At BMC, research is always in progress.

Learn more biomedcentral.com/submissions 